\title{
In Vitro Eye-Blink Classical Conditioning Is NMDA Receptor Dependent and Involves Redistribution of AMPA Receptor Subunit GluR4
}

\author{
Joyce Keifer \\ Neuroscience Group, Division of Basic Biomedical Sciences, University of South Dakota School of Medicine, Vermillion, \\ South Dakota 57010
}

\begin{abstract}
The classically conditioned vertebrate eye-blink response is a model in which to study neuronal mechanisms of learning and memory. A neural correlate of this response recorded in the abducens nerve can be conditioned entirely in vitro using an isolated brainstem-cerebellum preparation from the turtle by pairing trigeminal and auditory nerve stimulation. Here it is reported that conditioning requires that the paired stimuli occur within a narrow temporal window of $<100 \mathrm{msec}$ and that it is blocked by the NMDA receptor antagonist D,L-2-amino-5phosphonovaleric acid. Moreover, there is a significant positive
\end{abstract}

correlation between the levels of conditioning and greater immunoreactivity with the glutamate receptor 4 (GluR4) AMPA receptor subunit in the abducens motor nuclei, but not with NMDAR1 or GluR1. It is concluded that in vitro classical conditioning of an abducens nerve eye-blink response is generated by NMDA receptor-mediated mechanisms that may act to modify the AMPA receptor by increasing GluR4 subunits in auditory nerve synapses.

Key words: eye blink; conditioning; in vitro; turtle; NMDA; GluR4
The classically conditioned eye-blink reflex is an established model for studies of the cellular mechanisms that underlie learning and memory (Bloedel and Bracha, 1995; Kim and Thompson, 1997). In this paradigm, an eye-blink reflex in response to a tone can be evoked when the tone is repeatedly paired with an air puff to the cornea that normally elicits the blink response. A neural correlate of the eye-blink reflex can be classically conditioned entirely in vitro using a brainstem preparation, with or without the cerebellum, from the turtle (Keifer et al., 1995; Anderson and Keifer, 1997, 1999). Activity recorded in the abducens nerve, which contains motor neuronal projections to the extraocular muscles controlling movement of the nictitating membrane and eyelid during a blink (Keifer, 1993), can be conditioned by pairing a trigeminal nerve unconditioned stimulus (US) with an auditory nerve conditioned stimulus (CS). These electrical stimuli represent analogs of the corneal air puff and tone used in behavioral studies, but in this case, they are applied directly to the cranial nerves. This classically conditioned abducens nerve response shows gradual acquisition of conditioned responses (CRs) to paired stimuli and extinction when the stimuli are unpaired. Acquisition of CRs is rapid, taking place in $\sim 2-3 \mathrm{hr}$ and thereby allowing in vitro studies of this poorly understood learning process.

Long-term potentiation (LTP), a form of activity-dependent synaptic plasticity that is likely to have a role in associative

Received Sept. 18, 2000; revised Dec. 15, 2000; accepted Jan. 8, 2001.

This work was supported by a Regents Research Award and National Institutes of Health Grants MH 58709 and P20 RR15567 that is designated as a Center of Biomedical Research Excellence. I thank Curt W. Anderson for participation in some of these experiments and James C. Houk, Ronald Lindahl, and N. Traverse Slater for helpful comments on a previous version of this manuscript. I also thank Tim Clark for generating the Western blots.

Correspondence should be addressed to Dr. Joyce Keifer, Neuroscience Group, Division of Basic Biomedical Sciences, University of South Dakota School of Medicine, 414 East Clark Street, Vermillion, SD 57069. E-mail: jkeifer@usd.edu. Copyright $\odot 2001$ Society for Neuroscience $0270-6474 / 01 / 212434-08 \$ 15.00 / 0$ learning, has been shown to mediate a cellular analog of classical conditioning of the siphon-withdrawal reflex of Aplysia (Murphy and Glanzman, 1997). The Hebbian-like form of LTP recorded from Aplysia, which has been extensively studied in neurons from hippocampal slices, requires a narrow temporal relation between the paired stimuli, activation of postsynaptic NMDA receptors, and intracellular $\mathrm{Ca}^{2+}$ entry (Malenka, 1994; Murphy and Glanzman, 1996, 1997; Bi and Poo, 1998; Soderling and Derkach, 2000). In the hippocampus, LTP is also associated with the modulation of AMPA receptors (Liao et al., 1995; Barria et al., 1997; Hayashi et al., 2000; Soderling and Derkach, 2000). One proposed mechanism for enhanced synaptic strength during learning-related forms of plasticity is the induction of functional AMPA receptors at "silent synapses" that contained previously only NMDA receptors (Malenka and Nicoll, 1997). Synapses that contain NMDA receptors alone are silent because at normal resting potentials the receptor or channel is blocked by extracellular $\mathrm{Mg}^{2+}$. During LTP, it is thought that AMPA receptors are delivered to synapses from nonsynaptic sites, rendering them to be functional. In support of this hypothesis, activity-dependent redistribution of AMPA receptors has been observed directly in cultured hippocampal neurons using fluorescence microscopy (Liao et al., 1999; Lissin et al., 1999; Shi et al., 1999). In this study, it is shown that in vitro classical conditioning of a vertebrate eye-blink reflex requires that the CS and US occur within a narrow temporal window of $<100 \mathrm{msec}$ and is NMDA receptor dependent. Moreover, conditioning is associated with upregulation of the AMPA receptor subunit glutamate receptor 4 (GluR4), but not of NMDAR1 or GluR1, in the abducens motor nuclei. These observations suggest that there is an NMDAdependent redistribution of AMPA receptor subunits during conditioning, findings that are consistent with the silent-synapse hypothesis.

Parts of this paper have been published previously (Keifer, 2000). 


\section{MATERIALS AND METHODS}

Conditioning procedures. Freshwater pond turtles Chrysemys picta were anesthetized by hypothermia and decapitated. The brainstem-cerebellum was bathed in physiological saline (2-4 $\mathrm{ml} / \mathrm{min}$ ) containing (in $\mathrm{mm}$ ): $100 \mathrm{NaCl}, 6 \mathrm{KCl}, 40 \mathrm{NaHCO}_{3}, 2.6 \mathrm{CaCl}_{2}, 1.6 \mathrm{MgCl}_{2}$, and 20 glucose, which was oxygenated with $95 \% \mathrm{O}_{2} / 5 \% \mathrm{CO}_{2}$ and maintained at room temperature $\left(22-24^{\circ} \mathrm{C}\right)$ (Keifer et al., 1995; Anderson and Keifer, 1997, 1999). Suction electrodes were used for stimulation and recording of cranial nerves. The US was a $2 \times$ threshold single-shock stimulus applied to the trigeminal nerve; the CS was a $100 \mathrm{~Hz}, 1 \mathrm{sec}$ train stimulus applied to the ipsilateral posterior root of the eighth nerve that was $\sim 75 \%$ of the threshold amplitude required to produce activity in the nerve. This latter nerve will be referred to as the auditory nerve. Neural activity was recorded from the ipsilateral abducens nerve. Timing parameters required to produce conditioning were investigated by using a CS-US interval of $10 \mathrm{msec}(n=5), 20 \mathrm{msec}(n=6), 60 \mathrm{msec}(n=5), 80 \mathrm{msec}$ $(n=5), 100 \mathrm{msec}(n=5), 300 \mathrm{msec}(n=4), 500 \mathrm{msec}(n=1), 1 \mathrm{sec}(n=$ $3)$, and $2 \sec (n=3)$. The CS-US interval is defined as the time between the offset of the CS and the onset of the US. The intertrial interval between the CS and the US was $30 \mathrm{sec}$. A pairing session consisted of 50 CS-US presentations followed by a $30 \mathrm{~min}$ rest period in which there was no stimulation. Seven additional preparations were tested for extinction of CRs in response to CS-US intervals of $300 \mathrm{msec}$ to $2 \mathrm{sec}$ after they were initially conditioned at the $0 \mathrm{msec}$ interval. CRs were defined as abducens nerve activity that occurred during the CS and had an amplitude of at least $25 \%$ of the unconditioned response (UR). The stimulus protocol was designed with some modification to be similar to those used in behavioral studies of the rabbit (see Keifer et al., 1995). Those experiments have typically used a CS ranging between 250 and $500 \mathrm{msec}$, although a $1 \mathrm{sec} C S$ produces conditioning. A $1 \mathrm{sec} C S$ was chosen for the in vitro turtle preparation because of its cooler temperature and relatively slower conduction time. Auditory nerve fibers in the turtle are most sensitive to stimuli between 100 and $500 \mathrm{~Hz}$, and therefore a CS of 100 $\mathrm{Hz}$ was used. Intertrial intervals were $30 \mathrm{sec}$, the average interval used in behavioral studies. The range of optimal conditioning parameters for this preparation has not yet been exhaustively examined. In addition to the pairing-specific acquisition of abducens nerve CRs, this in vitro preparation exhibits other features observed during conditioning experiments in rabbits. These include suppression of the UR during application of the paired stimuli and a shift in the latency of the CR toward the occurrence of the US with training (Anderson and Keifer, 1997).

Pharmacology. The NMDA receptor antagonist D,L-2-amino-5phosphonovaleric acid (AP-5; $100 \mu \mathrm{M}$; Tocris) was dissolved in physiological saline and perfused through the bath. In some experiments, application was performed throughout the conditioning procedure to test for effects on the induction of CRs. In other experiments, AP-5 was applied after the end of the third pairing session to test for effects on CR expression after conditioning had been obtained. In these experiments, AP-5 was perfused through the bath for two additional pairing sessions and was washed out for $40 \mathrm{~min}$, and conditioning was resumed in normal saline to test for recovery. A high-threshold auditory nerve-evoked abducens nerve response was also tested for habituation in AP-5. A high-intensity $(\sim 4-5 \times$ threshold) train stimulus applied to the auditory nerve evokes a burst discharge in the ipsilateral abducens nerve at monosynaptic latencies (Keifer et al., 1995). This response is thought to represent the blink component of a neural analog of the behavioral "startle" response, and it normally habituates to repeated stimuli. Here, AP-5 $(100 \mu \mathrm{M})$ was applied to the bath, and as during the conditioning procedure, a $100 \mathrm{~Hz}, 1 \mathrm{sec}$ train stimulus (the same as the CS but of greater amplitude) was applied to the auditory nerve in blocks of 50 stimuli per session, at an interval of $30 \mathrm{sec}$, and followed by a 30 min rest period.

Immunocytochemistry. After the physiological experiments, brainstem-cerebellum preparations were immersion fixed in cold 3\% paraformaldehyde (Keifer and Carr, 2000). Tissue sections were cut at $30 \mu \mathrm{m}$ and were preincubated in 10\% normal goat serum for $1 \mathrm{hr}$ followed by incubation in primary antibody overnight at $4{ }^{\circ} \mathrm{C}$ with gentle shaking. The primary antibodies used were a monoclonal antibody raised in mouse that recognizes NMDAR1 and polyclonal antibodies raised in rabbit that recognize GluR1 or GluR4 (PharMingen, San Diego, CA). The GluR1 and GluR4 antibodies recognize both flip and flop splice variants. An antibody that recognizes GluR2/3 in turtles has been obtained recently, and these results will be described elsewhere. Concentrations of primary antibodies were 1:100, except for NMDAR1 that was 1:1000. Triton $\mathrm{X}-100(0.1 \%)$ was used during incubation with primary antibodies to
GluR4. After the primary antibody, sections were incubated in a secondary antibody for $1-2 \mathrm{hr}$ using a concentration of 1:100. The secondary antibodies were indocarbocyanine-3 (Cy3) or Cy2-conjugated goat antimouse or goat anti-rabbit IgGs (Jackson ImmunoResearch, West Grove, PA) that were used to visualize the primary antibodies. The primary antibodies developed in mammals were likely to have maintained their specificity in turtles because glutamate receptor subunits are highly conserved and immunoblot analysis shows that they recognize similar molecular weight structures in birds compared with mammals. Moreover, the pattern of staining in the turtle brainstem is similar to that described for rats (Keifer and Carr, 2000). The secondary antibodies were tested for their specificity by several procedures described in Keifer and Carr (2000).

Digital images of immunofluorescence from tissue sections containing the principal and accessory abducens motor nuclei were captured using a video camera-equipped Zeiss Axioskop Mot-2 microscope. Quantitative image analysis was performed by using Adobe Photoshop software. The histogram feature calculates the average luminosity level and SD of the pixels in the selected field. Values were obtained for label in the principal and accessory abducens motor nuclei, and background values taken from unlabeled areas were subtracted from these for every section analyzed to control for variations in staining. Generally, 6-10 sections were analyzed and averaged for each case. The analysis was performed blind to the results of the conditioning experiment. StatView software was used for statistical analysis.

Western blot analysis. Turtle brainstems or mouse hippocampi were lysed in Laemmli buffer and centrifuged, and the supernatant was loaded on a $10 \%$ polyacrylamide minigel (Bio-Rad, Hercules, CA) and separated by gel electrophoresis. Proteins were transferred from the gel by electroblotting onto polyvinylidene difluoride membranes in blocking buffer containing $5 \%$ nonfat milk for $30 \mathrm{~min}$. The membranes were incubated with the primary antibody to GluR4 (1:100 dilution), washed, and incubated in HRP-conjugated goat anti-rabbit $\operatorname{IgG}$ secondary antibody (Vector Laboratories, Burlingame, CA). Immunoreactivity was visualized by chemiluminescence.

\section{RESULTS}

Classical conditioning of the in vitro abducens nerve response was obtained previously by using a delay conditioning paradigm (Keifer et al., 1995; Anderson and Keifer, 1997, 1999). During this procedure, a 1-sec-duration CS is applied to the auditory nerve and is followed immediately by a single-shock stimulus applied to the trigeminal nerve (i.e., a CS-US interval of $0 \mathrm{msec}$; the CS-US interval is defined as the time between the offset of the CS and the onset of the US). In the present study, the temporal parameters of the CS and US required to produce conditioning of the abducens nerve response were investigated by changing the CS-US interval to values ranging from $10 \mathrm{msec}$ to $2 \mathrm{sec}$ (Fig. 1A). When the percentage of preparations that conditioned using these CS-US intervals was examined, the results showed that there is a narrow temporal window between the occurrence of the CS and US in which conditioning can be produced. These results are summarized in Figure $1 B$. Preparations presented with CS-US intervals ranging from $300 \mathrm{msec}$ to $2 \mathrm{sec}$ failed to produce CR acquisition $(n=11$; Fig. $1 B)$. No CRs were recorded from any of these preparations during five sessions of pairing. Extinction of CRs also occurred in response to these CS-US delays (Fig. 2). After conditioning had been obtained initially using the 0 -msecdelay stimulus paradigm ( $n=7$; Fig. 2 , pairing sessions $1-3)$, the CS-US delay was changed from $300 \mathrm{msec}$ to $2 \mathrm{sec}$, and the percentage of recorded CRs decreased (Fig. 2, pairing sessions 4-6). Reacquisition was obtained when the stimulus paradigm was returned to the $0 \mathrm{msec}$ delay (Fig. 2, pairing sessions 7-10). These data suggest that intervals from $300 \mathrm{msec}$ to $2 \mathrm{sec}$ do not support abducens nerve CRs. However, when the CS and US were separated by an interval of not $>100 \mathrm{msec}(n=26)$, the percentage of preparations that conditioned gradually increased as the interval became smaller $\left(R^{2}=0.87 ; p=0.0001\right)$ until 


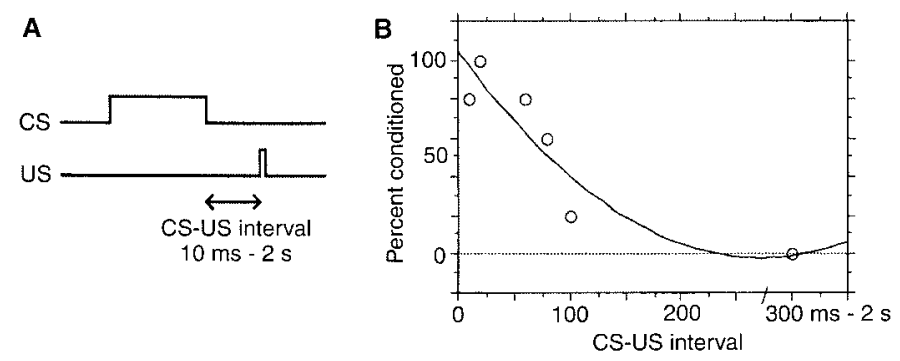

Figure 1. A, Schematic diagram illustrating the classical conditioning paradigm. The $1 \mathrm{sec}$ duration CS applied to the auditory nerve precedes the single-shock US applied to the ipsilateral trigeminal nerve. The delay between the offset of the CS and the onset of the US ranged from $10 \mathrm{msec}$ to $2 \mathrm{sec}$. $B$, The percentage of preparations that exhibited conditioning plotted as a function of the CS-US interval. CS-US intervals of $300 \mathrm{msec}$ to $2 \mathrm{sec}$ failed to produce conditioning in all preparations tested. However, when the CS and US were separated by not $>100 \mathrm{msec}$, the percentage of preparations that conditioned gradually increased as the interval became smaller and peaked at a CS-US interval of $20 \mathrm{msec}$. Each circle represents the mean of at least five experiments.

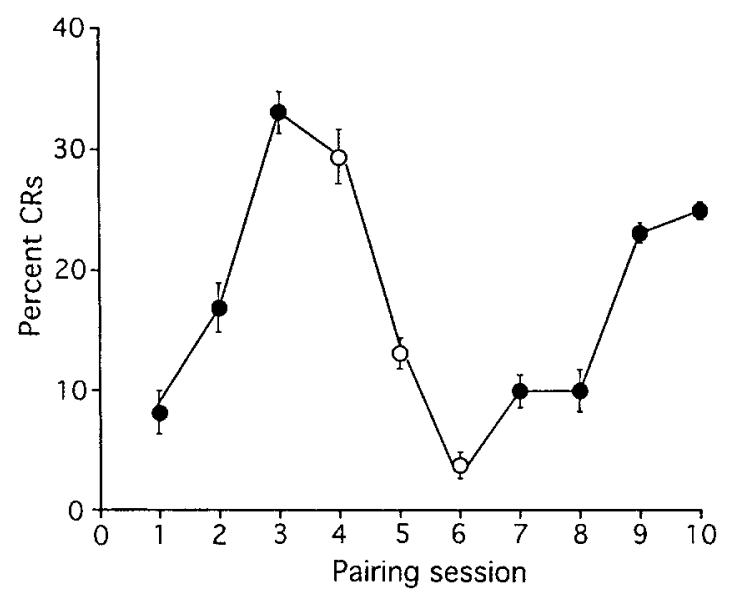

Figure 2. Summary data from seven preparations that had been conditioned initially to a mean of $34 \%$ CRs using a CS-US interval of $0 \mathrm{msec}$ ( filled circles; pairing sessions 1-3). Intervals of $300 \mathrm{msec}$ to $2 \mathrm{sec}$ resulted in extinction of CRs to a mean of 4\% (open circles; pairing sessions 4-6). Resumption of paired stimuli at the $0 \mathrm{msec}$ interval resulted in reacquisition of abducens nerve CRs to a mean of $24 \%$ (filled circles; pairing sessions $7-10)$.

conditioning peaked using an interval of $20 \mathrm{msec}$ (Fig. 1B). There was no significant correlation in the average percentage of CRs that were recorded among experiments within the $100 \mathrm{msec}$ interval $\left(R^{2}=0.05 ; p=0.28\right)$. Thus, precise timing constraints between the CS and US are required to produce abducens nerve conditioning.

To begin to analyze cellular mechanisms of conditioning in this preparation, we tested the hypothesis that classical conditioning of the abducens nerve response was mediated by NMDA receptors. Previous studies have shown that the turtle blink reflex pathways use both NMDA and AMPA receptors (Keifer, 1993; Keifer and Carr, 2000). In normal physiological saline, the abducens eye-blink response has a short-latency, short-duration burst component and a later, long-duration component (Fig. 3A, upper trace). Dual-component blink responses have been observed in all vertebrate species that have been studied (Pellegrini et al., 1995). Bath application of the NMDA receptor antagonist AP-5 blocked the long-duration component of the reflex while leaving the short-duration component unaffected, as is shown in Figure $3 A$ (compare the UR in the lower trace with that in the upper trace) (Keifer, 1993). The long-duration component of the reflex originates from the medullary reticular formation and is not necessary for conditioning, nor is it affected by the occurrence of the CR (Keifer, 1993; Anderson and Keifer, 1999). In the present experiments, AP-5 was used to determine whether induction of CRs was blocked when training was performed in the presence of the drug or whether the expression of CRs was disrupted when the drug was applied after conditioning had been obtained. When preparations were initially conditioned in the presence of AP-5 $(100 \mu \mathrm{M})$, none demonstrated abducens nerve CRs in four sessions of CS-US pairing at $0 \mathrm{msec}$ delay $(n=9$; Fig. $3 B)$. In experiments in which conditioning was conducted in normal physiological saline, CRs were recorded in the abducens nerve (Fig. $3 A$, upper trace, arrow). When AP-5 was applied to the bath after $\mathrm{CRs}$ had been acquired in normal saline (Fig. 3C, pairing sessions 1-3), they were significantly attenuated (Fig. $3 A$, lower trace, $C$, pairing sessions 4,$5 ; p<0.001)$. The $\mathrm{CRs}$ were again recorded when AP-5 was washed out of the bath (Fig. $3 C$, pairing sessions 6 , 7 ). It is notable that the percentage of CRs after AP-5 washout was approximately the same as that before the drug application. This suggests that CRs were not reacquired during this phase of conditioning but rather that their expression had recovered. Application of $100 \mu \mathrm{M}$ AP-5 does not affect habituation, a nonassociative form of learning. When a high-intensity stimulus is applied to the auditory nerve, it evokes a monosynaptic abducens nerve discharge that is believed to represent the blink component of a neural analog of the behavioral startle response. This response habituates in normal saline to repeated stimuli (Keifer et al., 1995). The effect of AP-5 appears to be specific to associative learning because this compound failed to block habituation of this high-threshold auditory nerve-evoked abducens nerve response. In AP-5, the mean percentage of responses in each stimulus session gradually habituated $(94,66,36,14$, and $4 \% ; n=6)$, similar to responses recorded in normal saline $(92,66,36,18$, and $4 \% ; n=3)$. These data suggest that abducens nerve classical conditioning requires NMDA receptor activation for both the induction and expression of CRs.

The recent findings that the functional properties of AMPA receptors are dependent on their subunit composition (Ozawa et al., 1998) and that this composition can be highly labile under some conditions (Liao et al., 1999; Lissin et al., 1999; Shi et al., 1999) are particularly relevant to studies of conditioning. Changes in number, distribution, or subunit composition of the postsynaptic receptors are viable mechanisms for synapse modification that may occur during learning. To investigate whether alterations in receptor subunit composition occur during conditioning of the in vitro abducens nerve response, immunocy tochemistry and light microscopy were used to localize NMDA and AMPA receptor subunits in the untrained turtle brainstem and cerebellum and in preparations that had undergone the conditioning procedure. Glutamate receptor subunit immunocytochemistry was performed on three groups of brainstem-cerebellum preparations: untrained preparations [from Keifer and Carr (2000)] that were placed immediately in fixative $(n=5)$, preparations that underwent the conditioning procedure but failed to acquire CRs ( $n=$ 2 ), and preparations that successfully acquired various levels of CRs $(n=12)$. Results from untrained preparations showed intense to moderate label for NMDAR1 and GluR1, and minimal label for GluR4, in the principal and accessory abducens motor nuclei (Keifer and Carr, 2000). Immunoreactivity levels of untrained versus trained preparations that failed to exhibit CRs 

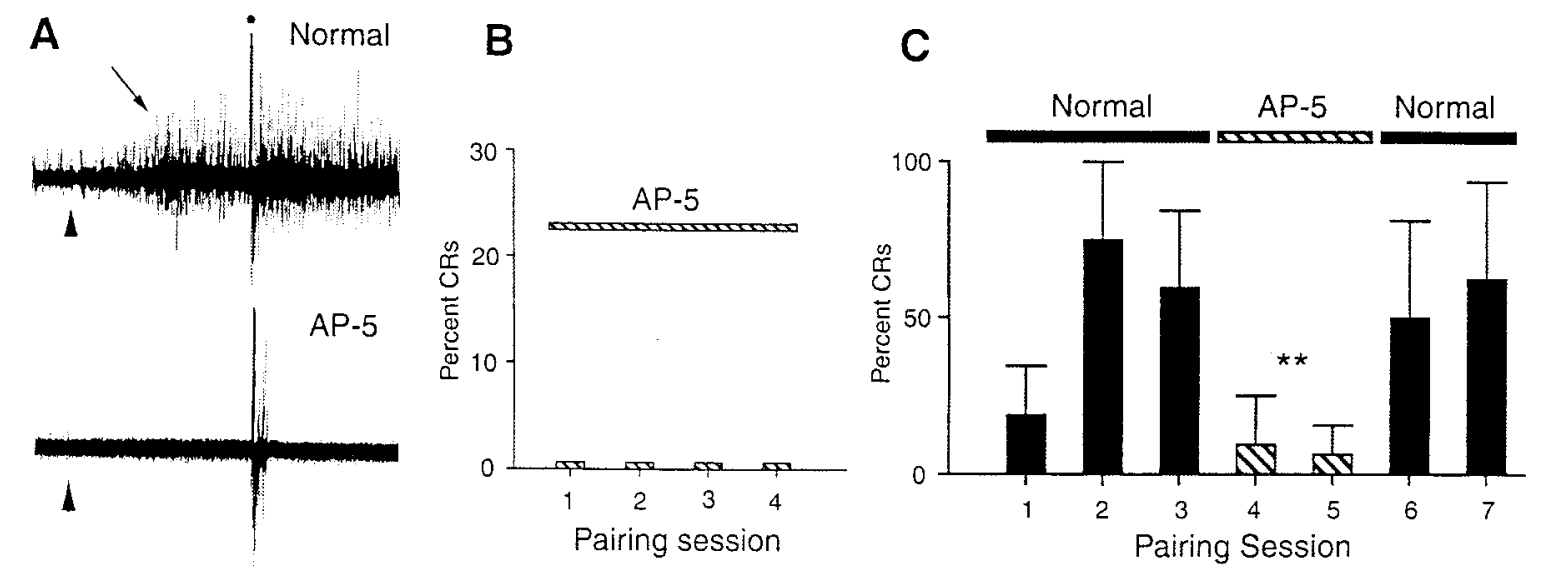

Figure 3. A, Abducens nerve recordings are shown during CS-US pairing in normal saline (upper trace) and in $100 \mu \mathrm{M}$ AP-5 (lower trace). In normal saline, the CR (arrow) and UR are recorded as burst discharges, and the UR demonstrates short- and long-duration components. In AP-5, CRs are generally not recorded, and the long-duration portion of the UR is blocked, leaving only the short-duration component. Each arrowhead indicates the start of the $1 \mathrm{sec}$ CS; the dot indicates the US. The CS-US delay in these recordings was 10 msec. $B$, Preparations that were presented with the conditioning protocol in the presence of AP-5 (hatched horizontal bar) failed to exhibit CRs in four sessions of CS-US pairing using a 0 msec delay $(n=$ 9). $C$, Bath application of AP-5 blocks the expression of abducens nerve CRs. Data from nine experiments are summarized. During the initial pairing sessions, a mean of $\sim 60-70 \%$ CRs was recorded ( filled vertical bars; pairing sessions 1-3). Application of AP-5 (hatched horizontal bar) resulted in attenuation in the percentage of CRs to a mean of $6 \%$ (hatched vertical bars; pairing sessions 4, 5). Approximately $60 \%$ of CRs on average were again recorded after washout of the drug ( filled vertical bars; pairing sessions 6, 7). Double asterisks indicate $p<0.001$ (ANOVA).
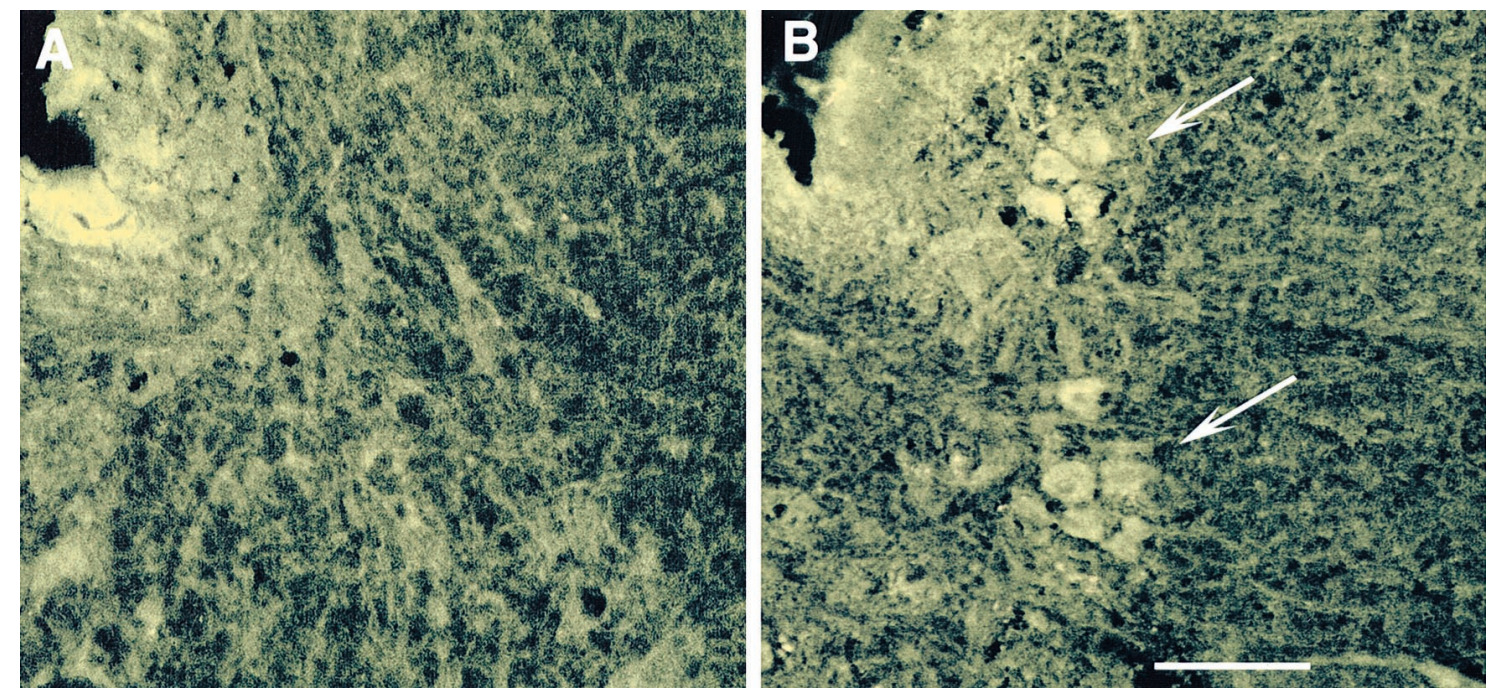

Figure 4. A, Photomicrograph of GluR4 immunoreactivity visualized by using a Cy2-conjugated secondary antibody in the principal abducens motor nucleus from an untrained preparation. $B$, A conditioned preparation that exhibited $98 \%$ CRs in the last pairing session. The arrows in $B$ indicate intensely GluR4-immunopositive abducens motor neurons from the conditioned preparation that are not apparent in the untrained preparation. Scale bar, $100 \mu \mathrm{m}$.

were not significantly different (principal abducens, $p=0.68$; accessory abducens, $p=0.61$; ANOVA). However, in preparations that exhibited acquisition of CRs, there was a visible and significant increase in AMPA receptor subunit immunoreactivity for GluR4 in the abducens motor neurons (Fig. 4). Photomicrographs show a clear increase in GluR4 immunoreactivity in the principal abducens motor neurons after conditioning (Fig. $4 B$ ) as compared with an unconditioned preparation (Fig. 4A). Similar results were observed for the accessory abducens nucleus. Quantitative image analysis of these immunocytochemical data was performed to examine the relationship between the degree of glutamate receptor subunit immunoreactivity of the abducens motor nuclei and the level of conditioning (Fig. 5). Images of the abducens motor nuclei from all preparations tested were analyzed using software that calculated the average luminosity of the pixels in the selected field. Analysis of NMDAR1 immunoreactivity in both the principal and accessory abducens motor nuclei (Fig. $5 A, D)$ failed to show a significant relationship between the level of NMDAR1 and the level of abducens nerve CRs $\left(R^{2}=0.001, p=\right.$ 0.93 , and $R^{2}=0.009, p=0.73$, respectively). Immunoreactivity for GluR1 also failed to show a significant correspondence with the level of conditioning; however, there was a trend toward reduced GluR1 immunoreactivity and a greater number of CRs in the accessory abducens nucleus (Fig. $5 B, E$; principal abducens, $R^{2}=0.02, p=0.53$; accessory abducens, $\left.R^{2}=0.17, p=0.08\right)$. On the other hand, there was a significant positive correlation between GluR4 immunoreactivity in the principal and accessory abducens motor nuclei and the expression of CRs (Fig. $5 C, F ; R^{2}$ 

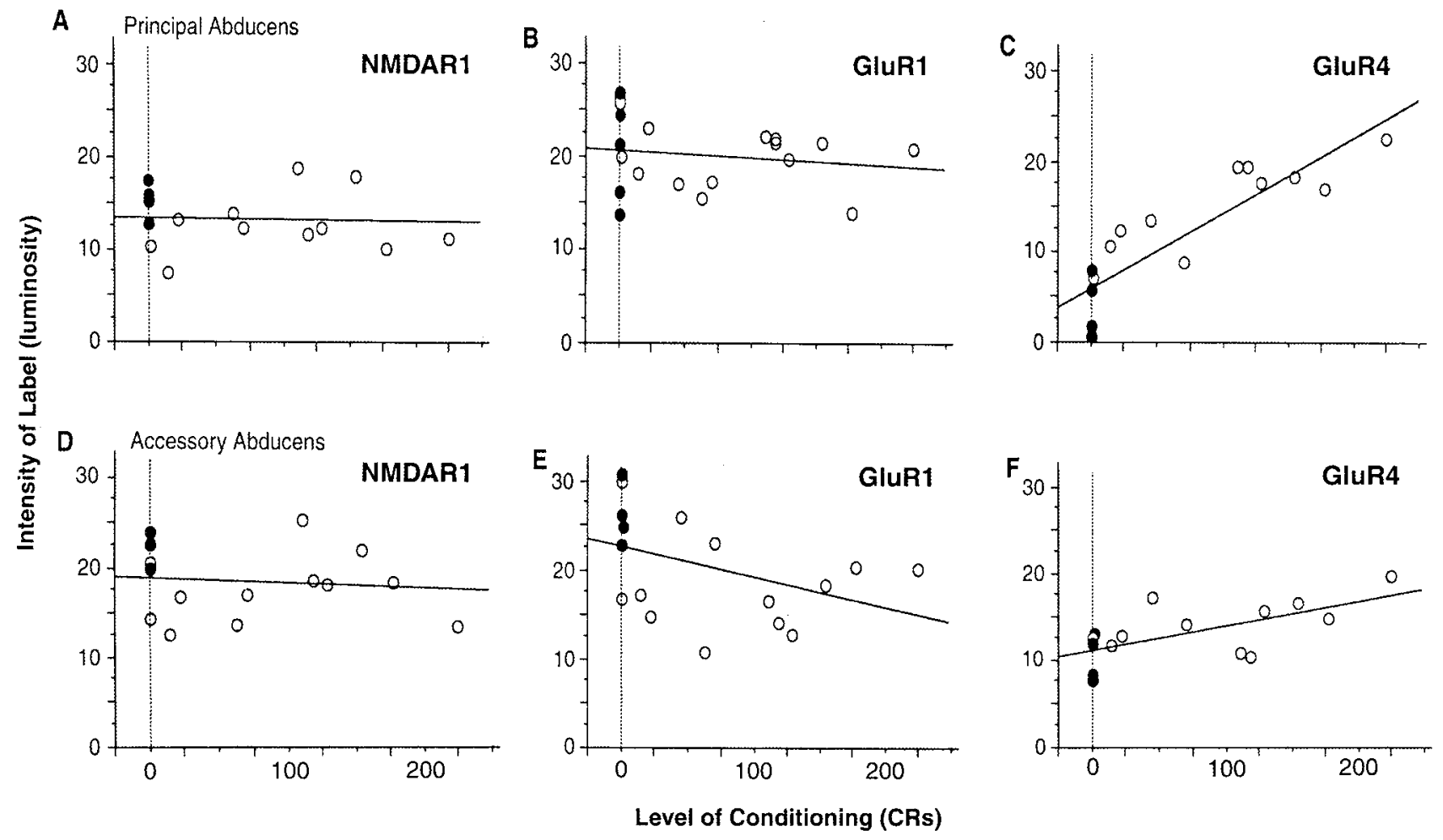

Figure 5. The intensity of immunoreactivity of the principal $(A-C)$ and accessory $(D-F)$ abducens motor nuclei is plotted as a function of the level of conditioning. Each circle represents an individual case; closed circles are untrained preparations, and open circles are preparations that underwent the conditioning procedure. Values plotted on the $y$-axis are in arbitrary numbers that represent average pixel luminosity. The total number of CRs recorded from individual preparations is plotted on the $x$-axis. $R^{2}$ values are given in the text.

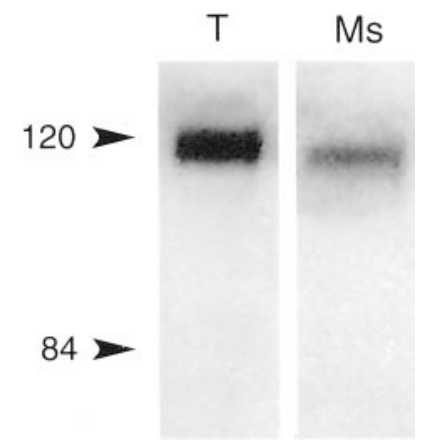

Figure 6. Western blot analysis of SDS gels of turtle $(T)$ brainstem and mouse $(M s)$ hippocampal tissue using antibodies to GluR4. For both the turtle and mouse tissue, a single band of $M_{\mathrm{r}}=\sim 108,000 \mathrm{kDa}$ migrated on the gels. Molecular weight markers are on the left.

$=0.74, p=0.0001$, and $R^{2}=0.42, p=0.009$, respectively). Thus, it appears that the GluR4 subunit, but not NMDAR1 or GluR1, is upregulated in the abducens motor nuclei during classical conditioning of the abducens nerve eye-blink response.

To verify the specificity of the GluR4 antibody in turtles, Western blot analysis was performed on turtle brainstem tissue and, for comparison, on mouse hippocampi. Immunoblots showed a single band that migrated to an $M_{\mathrm{r}}$ of $\sim 108,000 \mathrm{kDa}$ for both the turtle and the mouse tissue (Fig. 6). This is similar in size to that reported previously for rat (Petralia and Wenthold, 1992) and bird (Levin et al., 1997) brain. Moreover, these findings are consistent with our previous immunocytochemical studies of the turtle brainstem that show a pattern of immunostaining with antibodies to NMDAR1, GluR1, and GluR4 similar to that described in rats (Keifer and Carr, 2000).

\section{DISCUSSION}

The present results support the hypothesis that vertebrate eyeblink classical conditioning involves NMDA receptor-mediated mechanisms and modification of the AMPA receptor. Indirect evidence suggests that classical conditioning of the mammalian eye-blink response involves NMDA receptor-dependent synaptic plasticity (Servatius and Shors, 1996; Kishimoto et al., 1997). Moreover, by the use of autoradiography to examine the hippocampus in rabbits that had been classically conditioned, the number of NMDA receptors was found to be unchanged with respect to that in unconditioned animals, whereas AMPA receptors were significantly increased (Tocco et al., 1991). These findings are consistent with the present results, although in this study it is unclear whether there are more AMPA receptors or more existing receptors that have incorporated GluR4 subunits. These initial findings on the mechanisms that underlie conditioning in this preparation are reminiscent of those that produce other types of synaptic plasticity such as LTP and long-term depression (LTD). First, there are strict timing constraints for the generation of LTP, LTD, and classical conditioning. Bi and Poo (1998) showed that a critical window of $<40 \mathrm{msec}$ was required between presynaptic and postsynaptic stimuli to generate either LTP or LTD in hippocampal cultures. Similar timing constraints of $<60$ msec between stimuli have been reported for synaptic modification in the electrosensory lobe of the electric fish (Bell et al., 1997). In the in vitro turtle brainstem-cerebellum, the CS and US must occur within $\sim 100 \mathrm{msec}$ to produce conditioning, and in hippocampectomized rabbits, an interval of $300 \mathrm{msec}$, but not 500 
msec, can support eye-blink conditioning (Moyer et al., 1990). It appears that the associative requirements for LTP, LTD, and classical conditioning all fall within a relatively narrow temporal range. Second, activation of NMDA receptors is required to produce some forms of LTP and LTD and classical conditioning. Induction of Hebbian LTP and LTD requires conjunctive presynaptic and postsynaptic activity to activate NMDA receptor function and allow $\mathrm{Ca}^{2+}$ entry (Malenka, 1994; Soderling and Derkach, 2000). Classical conditioning also requires NMDA receptor function (Servatius and Shors, 1996; Kishimoto et al., 1997; Murphy and Glanzman, 1997) (the present study). Furthermore, the importance of $\mathrm{Ca}^{2+}$ influx in associative changes in synaptic efficacy was demonstrated by showing that postsynaptic injection of $\mathrm{Ca}^{2+}$ chelators attenuated conditioning in Aplysia (Murphy and Glanzman, 1996; Bao et al., 1998). An instrumental role for intracellular $\mathrm{Ca}^{2+}$ in the generation of eye-blink conditioning has yet to be shown. Third, evidence suggests that there is a modification of the AMPA receptor during LTP (Liao et al., 1995; Barria et al., 1997; Hayashi et al., 2000; Soderling and Derkach, 2000) and perhaps LTD (Lüthi et al., 1999). Receptor modifications may include phosphorylation that enhances AMPA receptor currents (Barria et al., 1997) or redistribution of AMPA receptor subunits at synaptic sites (Liao et al., 1995; Lissin et al., 1999; Shi et al., 1999; Hayashi et al., 2000). Such AMPA receptor alterations may also occur during classical conditioning (Tocco et al., 1991) (the present study). Further studies, such as protein analysis, will be required to provide more detail regarding changes in postsynaptic receptors and their underlying mechanisms during in vitro eye-blink conditioning.

Previous studies of in vitro classical eye-blink conditioning from the turtle have suggested that mechanisms underlying acquisition of CRs can be separated from those that generate the appropriate timing of CRs (Anderson and Keifer, 1997, 1999). Anderson and Keifer (1999) demonstrated that abducens nerve CR acquisition could be obtained from a highly reduced preparation consisting of an $\sim 4$-mm-thick section of brainstem tissue extending from the trigeminal to the glossopharyngeal nerve and containing a portion of the abducens eye-blink reflex circuitry. In these preparations, the UR has only the short-duration component, similar to that produced in the presence of AP-5. The long-duration component of the reflex, which is mediated by NMDA receptors, is conveyed through the medullary reticular formation that is eliminated by removal of the medulla. The properties of acquisition and extinction of CRs in reduced brainstems are similar to those in brainstem-cerebellum preparations; however, quantitative analysis reveals that the CRs have abnormally short onset latencies. These findings are similar to those of Perrett et al. (1993) who found that short-latency CRs were produced after lesions of the cerebellar cortex in rabbits. Furthermore, in vitro preparations lacking a cerebellum show an attenuation in the training-related shift in CR onset latency to later in the CS (Anderson and Keifer, 1999). These data suggest that there are mechanisms for CR acquisition within the brainstem abducens eye-blink circuitry, whereas the learned timing of CRs is controlled by the cerebellum.

Taken together, the findings from in vitro classical eye-blink conditioning in the turtle allow the outline of a model of the cellular events that may lead to CR acquisition (Fig. 7). From the data above, the model assumes that acquisition of CRs occurs locally within the blink reflex circuitry. This assumption is justified based on the fact that brainstem preparations demonstrate conditioning (Anderson and Keifer, 1999) and on preliminary

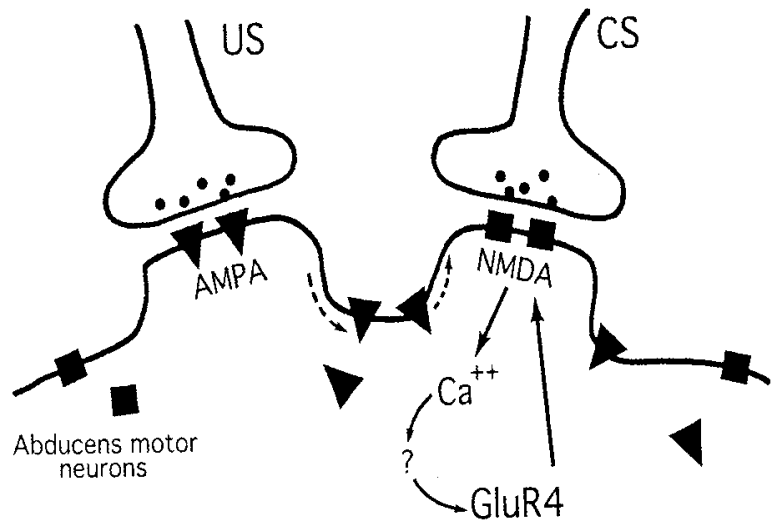

Figure 7. A model showing proposed postsynaptic mechanisms underlying classical conditioning of the in vitro abducens nerve response in the turtle. Evidence suggests that inputs from the US and CS directly contact abducens motor neurons. The US is conveyed primarily by AMPA receptors (triangles); synapses from the CS contain mainly NMDA receptors (squares), but AMPA receptors are present extrasynaptically. During conditioning, the strongly depolarizing US is proposed to drive AMPA receptors away from trigeminal nerve synapses into nearby auditory nerve synapses (dashed arrows) that are normally silent to the weak CS input. Accumulation of AMPA receptors allows depolarization of auditory nerve synapses in response to glutamate release, allowing $\mathrm{Ca}^{2+}$ entry through NMDA receptors. A series of unknown biochemical events, indicated by the question mark, leads to a modification of the GluR4 AMPA receptor subunit, and these events are targeted to auditory nerve synapses and underlie the generation of the CR. Small filled circles represent synaptic vesicles.

data suggesting that brainstem conditioning is NMDA receptor dependent and also results in increased GluR4 in the abducens nuclei (J. Keifer, unpublished observations). Both physiological and immunocytochemical studies confirm the presence of NMDA and AMPA receptors in the abducens blink reflex pathway (Keifer, 1993; Keifer and Carr, 2000). Although the model shown in Figure 7 emphasizes the abducens motor neurons as a site of conditioning, the principal sensory trigeminal nucleus cannot be excluded. Also, the present model does not address the findings related to timing of CRs that appear to be a function of the cerebellar circuitry (Anderson and Keifer, 1997, 1999). Tracttracing studies suggest that inputs from the trigeminal and auditory nerves to the abducens motor nuclei are direct (Herrick and Keifer, 1998), and recordings of reflex and single-unit latencies show that they are likely to be monosynaptic (Keifer, 1993; Keifer et al., 1995; Herrick and Keifer, 1998). The trigeminal nerveevoked blink reflex produced by the US is mediated predominantly by AMPA receptors. The long-duration, NMDA receptormediated component of the reflex is conveyed by a pathway through the medullary reticular formation and is not necessary for conditioning (Keifer, 1993; Anderson and Keifer, 1999). Other polysynaptic pathways linking trigeminal nerve inputs with abducens motor neurons in the brainstem cannot be excluded and may include the principal sensory trigeminal nucleus. The highthreshold auditory nerve-evoked startle reflex is AMPA receptor mediated because it is blocked by CNQX. However, a decrement in its amplitude in AP-5 in some cases suggests a weak NMDA receptor-mediated component (Keifer, unpublished observations). One parsimonious explanation for these results is that NMDA receptors are located at auditory nerve synaptic junctions and that AMPA receptors are located extrasynaptically. With this arrangement, NMDA receptors alone would be activated by the weak CS and thus produce no response, whereas a strong stimulus 
to the nerve may cause glutamate to spill over to nearby AMPA receptors and produce the startle response. This scenario for trigeminal and auditory nerve synapses onto abducens motor neurons is illustrated in Figure 7.

During conditioning, the present results show that NMDA receptors must be activated, presumably to allow intracellular $\mathrm{Ca}^{2+}$ entry, and that there is upregulation of the GluR4 subunit of the AMPA receptor in the abducens motor nuclei. Assuming the synapse-receptor arrangement in Figure 7, there must be a mechanism for the auditory nerve CS to activate postsynaptic NMDA receptors or channels. Although many scenarios may be considered, one possibility is that existing extrasynaptic or intracellular AMPA receptors are driven away from synapses that are depolarized by the US and move into nearby silent auditory nerve synapses (Fig. 7). Lissin et al. (1999) have shown in cultured neurons that GluR1 subunits rapidly redistribute away from synapses after application of glutamate. In time, accumulation of AMPA receptors results in sufficient depolarization of the synapse by the CS so that NMDA receptors are released from their $\mathrm{Mg}^{2+}$ block and allow intracellular $\mathrm{Ca}^{2+}$ entry as conditioning proceeds. Intracellular $\mathrm{Ca}^{2+}$ initiates a series of as yet unknown biochemical events that result in enhanced incorporation of the AMPA receptor subunit GluR4 into auditory nerve synapses that underlies the CR. The requirement for paired CS-US input for conditioning can be accommodated by the model. Stimulation of the US alone will not generate conditioning because, even if the AMPA receptors are redistributed, NMDA receptors will not be activated by the $\mathrm{CS}$ to allow $\mathrm{Ca}^{2+}$ entry. Stimulation of the $\mathrm{CS}$ alone or of the CS before the US will have no effect because these synapses are normally silent to weak input. The model is necessarily speculative because not enough is known about the cellular events leading to eye-blink conditioning, and there are many possibilities. The model assumes that conditioning takes place within the abducens motor neurons, in part because they receive convergent CS and US inputs. However, this may not be the case. The principal sensory trigeminal nucleus may also participate in conditioning of the blink reflex, but connections with the abducens motor neurons are as yet unspecified. Another point to consider when revising the model is that the results show weakly GluR4-immunopositive abducens motor neurons in unconditioned preparations and intensely immunopositive neurons in those that conditioned. This finding leaves open the question of whether GluR4 subunits are newly synthesized during conditioning or whether there is a post-translational modification of the $\mathrm{C}$ terminal that allows them to be better recognized by the antibodies.

The finding that the GluR4 subunit of the AMPA receptor was modified during conditioning was unexpected, especially in view of the reports of activity-dependent modification of the GluR1 subunit (Barria et al., 1997; Liao et al., 1999; Lissin et al., 1999; Shi et al., 1999). However, the present data do not exclude redistribution of GluR1 or NMDAR1 during conditioning. Immunostaining has revealed that the GluR4 subunit is especially dense in the auditory brainstem, particularly among nuclei that are contacted by auditory nerve fibers (Rubio and Wenthold, 1997). Additionally, AMPA receptors that contain GluR4 generate currents that decay rapidly and thereby mediate fast neuronal transmission, a necessary feature of the auditory system (Mosbacher et al., 1994). Tract-tracing studies in turtles have shown that the abducens motor nuclei are directly contacted by the auditory nerve (Herrick and Keifer, 1998). Therefore, it is plausible that GluR4 AMPA receptor subunits are targeted to audi- tory nerve synapses by an NMDA receptor-dependent process to strengthen the CS input during conditioning that results in the generation of CRs.

\section{REFERENCES}

Anderson CW, Keifer J (1997) The cerebellum and red nucleus are not required for in vitro classical conditioning of the turtle abducens nerve response. J Neurosci 17:9736-9745.

Anderson CW, Keifer J (1999) Properties of in vitro turtle conditioned abducens nerve responses in the absence of the sustained component of the UR. J Neurophysiol 81:1242-1250.

Bao J-X, Kandel ER, Hawkins RD (1998) Involvement of presynaptic and postsynaptic mechanisms in a cellular analog of classical conditioning at Aplysia sensory-motor neuron synapses in isolated cell culture. J Neurosci 18:458-466.

Barria A, Muller D, Derkach V, Griffith LC, Soderling TR (1997) Regulatory phosphorylation of AMPA-type glutamate receptors by CaMKII during long-term potentiation. Science 276:2042-2045.

Bell CC, Han VZ, Sugawara Y, Grant K (1997) Synaptic plasticity in a cerebellum-like structure depends on temporal order. Nature 387:278-281.

Bi G-Q, Poo M-M (1998) Synaptic modifications in cultured hippocampal neurons: dependence on spike timing, synaptic strength, and postsynaptic cell type. J Neurosci 18:10464-10472.

Bloedel JR, Bracha V (1995) On the cerebellum, cutaneomuscular reflexes, movements control and the elusive engrams of memory. Behav Brain Res 68:1-44.

Hayashi Y, Shi S-H, Esteban JA, Piccini A, Poncer J-C, Malinow R (2000) Driving AMPA receptors into synapses by LTP and CaMKII: requirement for GluR1 and PDZ domain interaction. Science 287:2262-2267.

Herrick JL, Keifer J (1998) Central trigeminal and posterior eighth nerve projections in the turtle Chrysemys picta studied in vitro. Brain Behav Evol 51:183-201.

Keifer J (1993) In vitro eye-blink reflex model: role of excitatory amino acids and labeling of network activity with sulforhodamine. Exp Brain Res 97:239-253.

Keifer J (2000) In vitro classical conditioning in turtles is NMDA receptor-dependent and involves redistribution of AMPA receptor subunit GluR4. Soc Neurosci Abstr 26:718.

Keifer J, Carr MT (2000) Immunocytochemical localization of glutamate receptor subunits in the brain stem and cerebellum of the turtle, Chrysemys picta. J Comp Neurol 427:455-468.

Keifer J, Armstrong KE, Houk JC (1995) In vitro classical conditioning of abducens nerve discharge. J Neurosci 15:5036-5048.

Kim JJ, Thompson RF (1997) Cerebellar circuits and synaptic mechanisms involved in classical eyeblink conditioning. Trends Neurosci 20:177-181.

Kishimoto Y, Kawahara S, Kirino Y, Kadotani H, Nakamura Y, Ikeda M, Yoshioka T (1997) Conditioned eyeblink response is impaired in mutant mice lacking NMDA receptor subunit NR2A. NeuroReport 8:3717-3721.

Levin MD, Kubke MF, Schneider M, Wenthold R, Carr CE (1997) Localization of AMPA-selective glutamate receptors in the auditory brainstem of the barn owl. J Comp Neurol 378:239-253.

Liao D, Hessler NA, Malinow R (1995) Activation of postsynaptically silent synapses during pairing-induced LTP in CA1 region of hippocampal slice. Nature 375:400-404.

Liao D, Zhang X, O'Brien R, Ehlers MD, Huganir RL (1999) Regulation of morphological postsynaptic silent synapses in developing hippocampal neurons. Nat Neurosci 2:37-43.

Lissin DV, Carroll RC, Nicoll RA, Malenka RC, von Zastrow M (1999) Rapid, activation-induced redistribution of ionotropic glutamate receptors in cultured hippocampal neurons. J Neurosci 19:1263-1272.

Lüthi A, Chittajallu R, Duprat F, Palmer MJ, Benke TA, Kidd FL, Henley JM, Collingridge GL (1999) Hippocampal LTD expression involves a pool of AMPARs regulated by the NSF-GluR2 interaction. Neuron 24:389-399.

Malenka RC (1994) Synaptic plasticity in the hippocampus: LTP and LTD. Cell 78:535-538.

Malenka RC, Nicoll RA (1997) Silent synapses speak up. Neuron 19:473-476.

Mosbacher J, Schoepfer R, Monyer H, Burnashev N, Seeburg PH, Rupersberg JP (1994) A molecular determinant for submillisecond desensitization in glutamate receptors. Science 266:1059-1062.

Moyer JR, Deyo RA, Disterhoft JF (1990) Hippocampectomy disrupts trace eye-blink conditioning in rabbits. Behav Neurosci 104:243-252.

Murphy GC, Glanzman DL (1996) Enhancement of sensorimotor connections by conditioning-related stimulation in Aplysia depends upon postsynaptic $\mathrm{Ca}^{2+}$. Proc Natl Acad Sci USA 93:9931-9936.

Murphy GG, Glanzman DL (1997) Mediation of classical conditioning in Aplysia californica by long-term potentiation of sensorimotor synapses. Science 278:467-471. 
Ozawa S, Kamiya H, Tsuzuki K (1998) Glutamate receptors in the mammalian central nervous system. Prog Neurobiol 54:581-618.

Pellegrini JJ, Horn AKE, Evinger C (1995) The trigeminally evoked blink reflex. I. Neuronal circuits. Exp Brain Res 107:166-180.

Perrett SP, Ruiz BP, Mauk MD (1993) Cerebellar cortex lesions disrupt learning-dependent timing of conditioned eyelid responses. J Neurosci 13:1708-1718.

Petralia RS, Wenthold RJ (1992) Light and electron immunocytochemical localization of AMPA-selective glutamate receptors in the rat brain. J Comp Neurol 318:329-354.

Rubio ME, Wenthold RJ (1997) Glutamate receptors are selectively targeted to postsynaptic sites in neurons. Neuron 18:939-950.
Servatius RJ, Shors TJ (1996) Early acquisition, but not retention, of the classically conditioned eyeblink response is $N$-methyl-D-aspartate (NMDA) receptor dependent. Behav Neurosci 110:1040-1048.

Shi S-H, Hayashi Y, Petralia RS, Zaman SH, Wenthold RJ, Svoboda K, Malinow R (1999) Rapid spine delivery and redistribution of AMPA receptors after synaptic NMDA receptor activation. Science 284:1811-1816.

Soderling TR, Derkach VA (2000) Postsynaptic protein phosphorylation and LTP. Trends Neurosci 23:75-80.

Tocco G, Devgan KK, Hauge SA, Weiss C, Baudry M, Thompson RF (1991) Classical conditioning selectively increases AMPA receptor binding in rabbit hippocampus. Brain Res 559:331-336. 